Fetal Diagnosis and Therapy

\title{
Fetuses with Isolated Congenital Heart Defects Show Normal Cerebral and Extracerebral Fluid Volume Growth: A 3D Sonographic Study in the Second and Third Trimester
}

\author{
F.A.R. Jansen ${ }^{a} \quad$ E.W. van Zwet $^{b} \quad$ S.M.P. Everwijn ${ }^{a} \quad$ A.K.K. Teunissen ${ }^{a}$ \\ L. Rozendaal ${ }^{c} \quad$ J.M.M van Lith ${ }^{a} \quad$ N.A. Blom ${ }^{c}$ M.C. Haak ${ }^{a}$ \\ a Leiden University Medical Centre, Department of Obstetrics and Fetal Medicine, Leiden, The Netherlands; \\ ${ }^{\mathrm{b}}$ Leiden University Medical Centre, Department of Medical Statistics, Leiden, The Netherlands; \\ 'Leiden University Medical Centre, Department of Paediatric Cardiology, Leiden, The Netherlands
}

\section{Keywords}

Congenital heart defects · Fetal cerebral growth - Brain

development of the fetus . 3D ultrasound

\begin{abstract}
Objective: The aim of our study is to explore whether the cerebral growth is delayed in fetuses with congenital heart defects (CHD) in the second and early third trimester. Methods: A prospective cohort study was conducted in $77 \mathrm{CHD}$ cases, with 75 healthy controls. 3D cerebral volume acquisition was performed sequentially. The volumes of the fetal hemicerebrum and extracerebral fluid were compared by linear regression analysis, and the Sylvian fissure was measured. Results: Between 19 and 32 weeks of gestation, 158 measurements in cases and 183 measurements in controls were performed (mean 2.2/subject). The volume growth of the hemicerebrum $\left(R^{2}=0.95\right.$ vs. $\left.0.95 ; p=0.9\right)$ and the extracerebral fluid ( $R^{2}=0.84$ vs. $\left.0.82, p=0.9\right)$ were similar. Fetuses with abnormal oxygen delivery to the brain have a slightly smaller brain at 20 weeks of gestation $(p=0.02)$, but this difference disappeared with advancing gestation. CHD cases demonstrated a slightly shallower Sylvian fissure (mean ratio
\end{abstract}

0.146 vs. $0.153 ; p=0.004)$. Conclusions: Our study shows no differences in cerebral growth, studied in an unselected cohort, with successive cases of isolated CHD. Even in the severest CHD cases, cerebral size is similar in the early third trimester. The cause and meaning of a shallower Sylvian fissure is unclear; possibly, it is a marker for delayed cerebral maturation or it might be an expression of decreasing amount of extracerebral fluid.

(c) 2019 The Author(s)

Published by S. Karger AG, Basel

\section{Introduction}

Congenital heart defects (CHD) are associated with cerebral abnormalities and neurodevelopmental delay, even in the absence of chromosomal or syndromal anomalies $[1,2]$. Neonatal ultrasound imaging studies demonstrate cerebral abnormalities in $15-75 \%$ of neonates with CHD prior to surgery [3-7]. Most cerebral findings in CHD newborns are mild, such as asymmetrical widened ventricles and increased extracerebral fluid. Neonatal MRI studies report delayed brain maturation and signs of cerebral atrophy [8]. These findings led to the hypothesis

\begin{tabular}{|c|c|}
\hline KARGER & $\begin{array}{l}\text { (c) } 2019 \text { The Author(s) } \\
\text { Published by S. Karger AG, Basel }\end{array}$ \\
\hline $\begin{array}{l}\text { E-Mail karger@karger.com } \\
\text { www.karger.com/fdt }\end{array}$ & $\begin{array}{l}\text { This article is licensed under the Creative Commons Attribution- } \\
\text { NonCommercial-NoDerivatives } 4.0 \text { International License (CC BY- } \\
\text { NC-ND) (http://www.karger.com/Services/OpenAccessLicense). } \\
\text { Usage and distribution for commercial purposes as well as any dis- } \\
\text { tribution of modified material requires written permission. }\end{array}$ \\
\hline
\end{tabular}

Fenna A.R. Jansen, MD

Leiden University Medical Centre

Department of Obstetrics - Prenatal Diagnosis and Fetal Therapy K6-P

Postbus 9600, NL-2300 RC Leiden (The Netherlands)

E-Mail f.a.r.jansen@lumc.nl 
that cerebral damage or altered cerebral development in fetuses with CHD already starts in the prenatal period, due to abnormal flow and oxygenation patterns [9].

Imaging studies in fetuses with CHD also report brain abnormalities, such as delay in head growth and brain sparing in subgroups of CHD [10-15]. The prenatal studies are, however, dominated by a series of severe CHD and left-sided CHD [13, 16, 17], and some studies also included cases with non-isolated CHD $[18,19]$. The reported variables, such as head circumference and flow indices, are very heterogeneous and were assessed at different gestational ages (GAs) [15]. Studies that perform multiple measurements per fetus, to assess changes over time, are very scarce. Furthermore, the methods to report the data vary between studies, hindering comparison and making general conclusion drawing difficult. Previous studies mainly focus on the third trimester, as this might be the period in which cortical folding and development accelerates. However, several studies show that at midgestation, fetal head circumference might already be delayed in certain $\mathrm{CHD}$, possibly even predicting developmental delay [20-22].

The purpose of this study was to investigate fetal brain volume and volume growth with ultrasound, in fetuses with CHD in the second and early third trimester. Additionally, extracerebral fluid space was studied, and the total cranial volume was compared as well. We aimed to assess an unselected consecutive cohort of isolated CHD fetuses and compare them with healthy control fetuses. We hypothesized to find smaller fetal brain volume and higher extracerebral fluid levels in CHD.

\section{Methods}

All women diagnosed with isolated fetal CHD referred to the LUMC between September 2013 and May 2016 were enrolled in this study after informed consent. All consecutive cases, detected before 32 weeks of gestation, were included. Healthy controls were recruited after a normal 20 weeks' standard anomaly scan in a lowrisk community practice, after informed consent. The research protocols were evaluated and approved by the local ethics committee. Exclusion criteria were ultrasound anomalies other than the $\mathrm{CHD}$, coinciding genetic or syndromal defects (prenatally diagnosed or postnatally apparent), and multiple gestation. Minor additional findings were not excluded, such as single umbilical artery, enlarged nuchal translucency without chromosomal defects, and small for GA without signs of placental insufficiency. GA was based on first-trimester ultrasound. In both groups, detailed sonography was performed after inclusion and repeated sequentially, after $2-5$ weeks. The examinations were performed by experienced sonographers (F.A.R.J./A.K.K.T./S.M.P.E.), using a Voluson E8 or E10 (GE Healthcare, Milwaukee, WI, USA) with a RAB 6-D probe.
The examination included the measurement of the depth of the Sylvian fissure (see online Supplement 1; for all online suppl. material, see www.karger.com/doi/10.1159/000488674). A 3D volume recording of the fetal brain was acquired at the plane of the head circumference measurement.

Offline postprocessing was performed using GE $4 \mathrm{D}$ viewer version 16, ext. 1. The observer was blinded to the clinical characteristics (presence or absence of CHD and GA). The Virtual Organ Computer-aided AnaLysis software tool (VOCAL, GE Healthcare) was used to manually trace the outline of the cerebral hemisphere, as well as the cavity of the hemicranium, excluding the infratentorial space and cerebellum. To achieve maximum visibility, we used the hemisphere furthest from the ultrasound probe (Fig. 1). The detailed description of the tracing methods and the intra- and interobserver reproducibility analysis are described in online Supplement 1 . The volumes of the cerebral hemisphere, extracerebral fluid spaces (including the lateral ventricle), and total hemicranial cavity were calculated in $\mathrm{cm}^{3}$.

The various heart defects (see online Supplement 3) were labelled according to the postnatal diagnosis (postnatal ultrasound). Major heart defects were defined as requiring surgery in the first year of life. Heart defects were grouped together for summary purposes as listed in Table 1. For the statistical analysis, CHD were clustered based on two aspects: oxygen delivery and flow to the brain. This method was previously described by our group [21]. For instance, the group with low or reduced oxygen delivery to the brain included transposition of the great arteries (TGA) (low oxygen) and univentricular CHD (mixed oxygen), and the normal oxygen group included pulmonary or aortic stenosis and persistent left caval vein with small LV (PLVCS). The group with reversed or diminished aortic arch flow included aortic hypoplasia or coarctation (diminished flow) and hypoplastic left heart syndrome (HLHS) (reversed flow), and the normal aortic arch flow group tetralogy of Fallot (TOF), TGA, and double outlet right ventricle (DORV) - in the absence of aortic obstruction. Irrespective of the other defects, several CHD can have left-sided/aortic obstruction. When for example a DORV TGA case also has a small aortic arch, they are categorized in group 2 diminished flow.

\section{Statistical Analysis and Data Handling}

Using the 3D measurements of the hemicerebral volume, extracerebral fluid volume, and hemicranial volume, the extracerebral fluid-to-brain volume ratio was calculated, as well as the percentage of the hemicranium consisting of fluid (ventricular and extracerebral). The hemicerebral volume-to-estimated fetal weight ratio was calculated (brain-weight ratio). The depth of the Sylvian fissure was displayed as ratio of the inner biparietal diameter (BPD). To account for fetal growth, the relation of various variables with the advancing gestation was evaluated with scatterplots, and the linearity of the data was assessed. Volume measurements underwent a logistic transformation to facilitate linear regression (exponential growth model), and the natural logarithm (ln) of the measurements were used for further statistical analysis. Comparison of (ln of) measurements at various GAs was performed by comparing linear correlations (equality of regression) in different subgroups, using a linear mixed regression model. Data are presented as $R^{2}$ or mean $\pm \mathrm{SD}$. Group means are compared by independent-sample $t$ test, and percentages are compared by $\chi^{2}$ analysis. $p<0.05$ was considered statistical significant. All analyses were performed in SPSS version 23.0.0.0 (IBM, Armonk, NY, USA). 


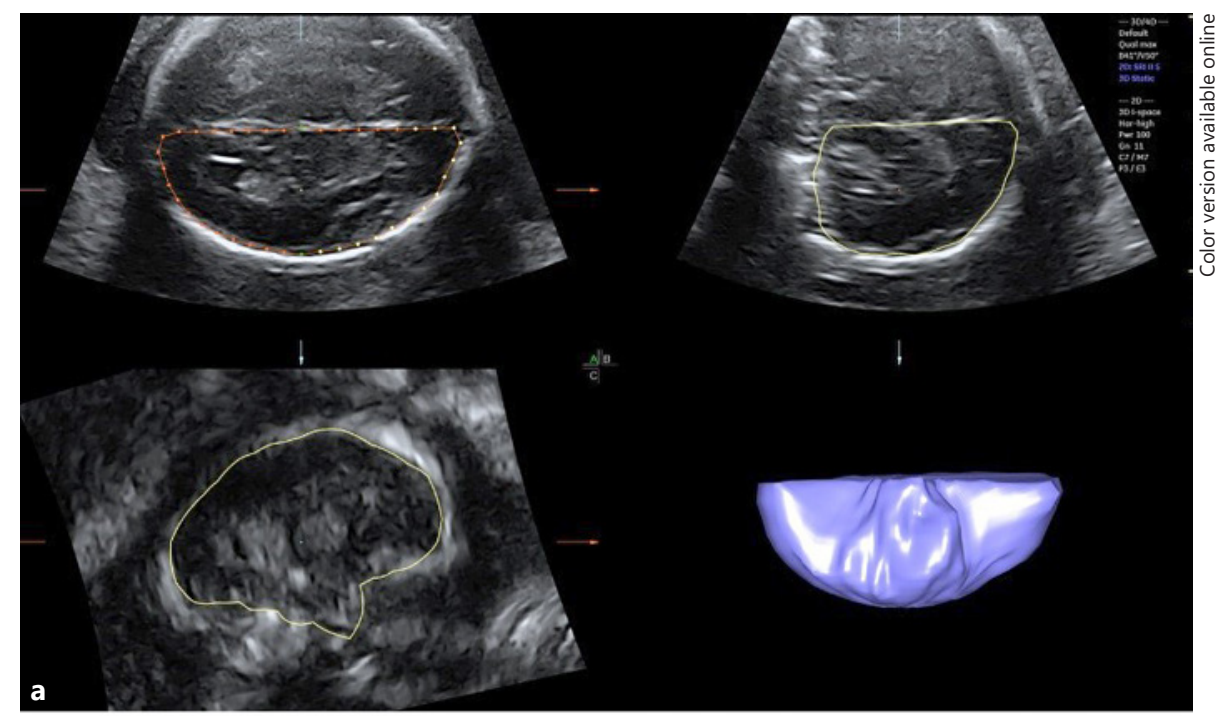

Fig. 1. a, b Tracing example of the hemicranium (left) and hemicerebrum (right).

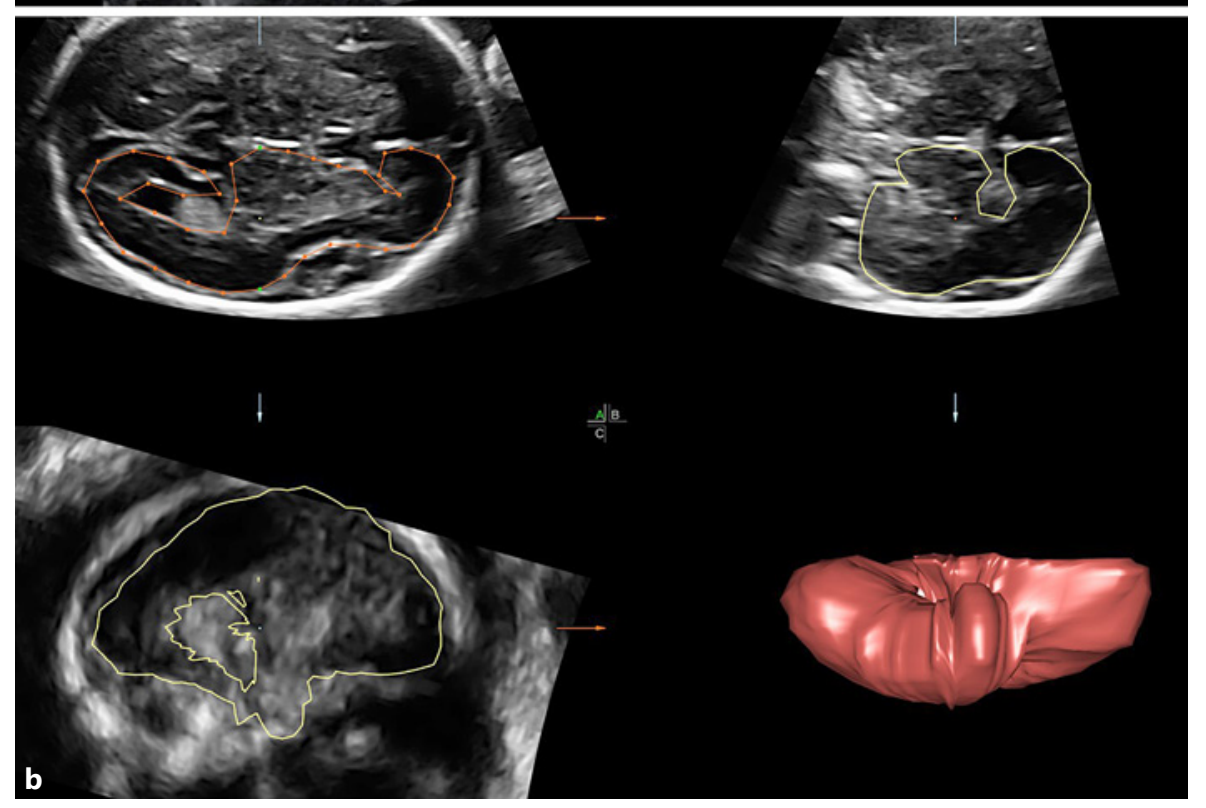

\section{Results}

Isolated CHD was diagnosed in 92 fetuses in the study period. Of these, 15 cases were excluded because of multiple gestation $(n=3)$, postnatal genetic abnormalities $(n=8)$, or a normal heart on postnatal ultrasound (these fetuses were suspected for coarctation; $n=4$ ). Thus, 77 cases were included for neurosonographic analysis. Postnatal confirmation was not possible in 12 cases (16\%) in which pregnancy termination was chosen, because parents did not give consent for postmortem examination. The type of CHD and the clustering with regard to cerebral oxygen delivery and aortic flow of the included cases are summarized in
Table 1, and a detailed description is available in online Supplement 3. Most CHD were major, and we included 8 minor CHD cases (10\%). Secondly, we enrolled 75 control cases. All control infants received a neonatal cranial ultrasound in the first week of life and showed normal postnatal development until at least 1 month postpartum.

In total, 158 examinations in 77 cases (mean 2.1 measurements per case) and 183 examinations in 75 controls (mean 2.4 measurements per control) were performed between GA 19+0 and GA 31+4 (mean GA at inclusion in cases $24+2$ and in controls $24+1$; not significant). In 13 recordings (4\%), the volume measurements were not possible due to poor quality. 
Table 1. Types of included congenital heart defects (CHD) and clustering on oxygen and flow

\begin{tabular}{lrr}
\hline Type of CHD & $n$ & $\%$ \\
\hline Hypoplastic left heart syndrome (HLHS) & 9 & 12 \\
(Other) left ventricular outflow tract obstructions* & 12 & 16 \\
Transposition of the great arteries (TGA) & 13 & 17 \\
Hypoplastic right heart syndrome & 8 & 10 \\
Tetralogy of Fallot/double outlet right ventricle - & & \\
$\quad$ Fallot type & 12 & 16 \\
Double outlet right ventricle - TGA type & 6 & 8 \\
(Un)balanced atrioventricular septal defect & 4 & 5 \\
other major CHD** & 5 & 6 \\
minor CHD*** & 8 & 10 \\
\hline Total & 77 & \\
\hline Oxygen delivery & & \\
Low (TGA) & 13 & 17 \\
Mixed & 43 & 56 \\
Normal & 21 & 27 \\
\hline Aorta flow & & \\
Reversed (HLHS) & 9 & 12 \\
Obstructed & 17 & 22 \\
Normal & 51 & 66 \\
\hline
\end{tabular}

* Includes aortic stenosis, shone syndrome, aortic arch hypoplasia or coarctation, interrupted aortic arch. ${ }^{* *}$ Includes congenitally corrected TGA, complex defects with tricuspid atresia and TGA, and truncus arteriosus. ${ }^{* * *}$ Includes persistent left superior caval vein, (small) ventricular septal defect, (mild) pulmonary stenosis, right aortic arch and restrictive foramen ovale.

The results of the hemicerebral volumes and extracerebral fluid volumes are summarized in Table 2. The mean volume of the hemicerebrum $\left(32.9\right.$ vs. $32.9 \mathrm{~cm}^{3}$; $p=0.9)$ and hemicranium ( 49.9 vs. $\left.50.8 \mathrm{~cm}^{3} ; p=0.7\right)$ were equal in cases compared to controls. The linear mixed regression model revealed no difference in hemicerebral volume growth (Table 2; Fig. 2), nor in the hemicranial volume and the extracerebral fluid space (Table 2). The hemicerebral volumes and growth velocity were assessed by type of CHD. The cluster with low or mixed oxygen delivery to the brain (grouped together as "abnormal" oxygen) appeared to have a smaller hemicerebral volume at midgestation, compared to CHD with normal oxygen delivery to the brain (ln of hemicerebrum 2.69 vs. 2.56 ; $p=$ 0.02 ). This difference disappeared with advancing gestation (at 28 weeks of gestation: $\ln$ of hemicerebrum 4.01 vs. $3.97 ; p=0.3$ ). Linear growth per week was slightly but not significantly - different (abnormal oxygen +0.18 vs. normal oxygen +0.16 ; $p=0.07$; Fig. 3 ). There were no differences in the hemicerebral volume or growth velocity between CHD cases with normal or abnormal aortic flow (linear growth per week +0.17 vs. +0.17 ; $p=0.9$ ).

The extracerebral fluid volume, as well as the various ratios, were not significantly different, comparing cases to controls (Table 2). The percentage of the hemicranium occupied by fluid trended towards diminishing with advancing gestation, as well as the fluid-to-brain ratio. In the online supplementary Figures S1-S5, this trend can also be identified in the ventricular volume growth, sinocortical distance, ventricular index, and lateral ventricle size measurements. These trends were, however, not statistically significant.

The difference in relative depth of the Sylvian fissure (Sylvian-BPD ratio) between cases and controls reached statistical significance. CHD cases demonstrated a slightly shallower Sylvian fissure (mean ratio 0.146 vs. 0.153 ; $p=0.004$; Table 2); there was no significant change with advancing GA in this ratio (linear growth per week in cases +0.005 vs. controls +0.004 ; $p=0.5$; Fig. 4).

\section{Discussion}

In this prospective study of consecutive isolated CHD cases compared to controls, a significant difference in hemicerebral volume and volume growth was absent in the second and early third trimester. CHD cases with reduced cerebral oxygen delivery such as TOF, DORV, TGA, and HLHS show a slightly smaller hemicerebral volume at 20 weeks of gestation, but this effect disappears with advancing gestation.

Previous MRI studies on brain volume or brain weight only report on third-trimester measurements, which makes comparison with our results difficult $[11,18,19$, 22-26]. Smaller brain volumes are previously demonstrated in mixed CHD types in the third trimester, but these studies comprise small cohorts and most importantly, they report on selected (severe), nonconsecutive cases, and some even included chromosomal abnormalities $[18,19]$. Smaller brain volumes in isolated HLHS cases in the third trimester have been reported, confirming the widely accepted hypothesis that HLHS fetuses demonstrate prenatal cerebral developmental and growth delay [25-27]. Our study included only 6 cases of HLHS with repeated measurements, because termination of the pregnancy was frequently chosen in cases with HLHS. In a retrospective cohort with 26 ongoing HLHS cases, we, however, did not find a deflecting head growth in this group [21]. When clustering our results on cerebral oxy- 


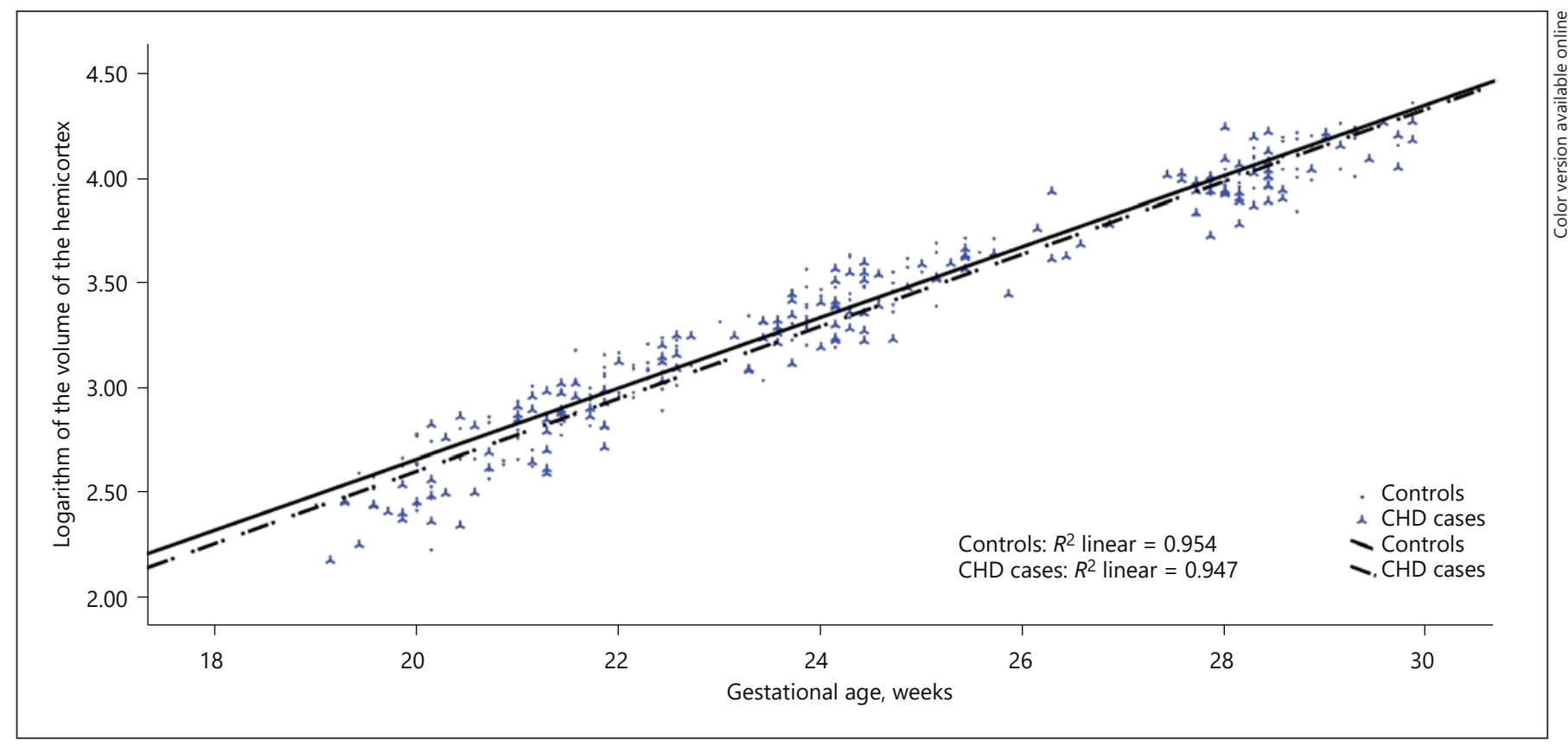

Fig. 2. Linear regression of the volume growth of the hemicerebrum; cases versus controls. Linear regression of the logarithmic transformation of the hemicerebrum measurements. No statistical differences were found (linear growth per week +0.17 vs. $+0.17 ; p=0.2$ ).

Table 2. Results of fetal hemicerebral and extracerebral fluid growth; cases versus controls

\begin{tabular}{|c|c|c|c|c|c|}
\hline Variable & CHD & & Controls & & \\
\hline$n$ & 160 & & 183 & & \\
\hline \multirow[t]{2}{*}{ 3D measurement not possible } & 4 & & 9 & & \\
\hline & Mean (SD) & $R^{2}$ & Mean (SD) & $R^{2}$ & $p$ value \\
\hline GA at ultrasound, weeks+days & $24+2$ (22 days) & & $24+1$ (21 days) & & 0.9 \\
\hline Estimated fetal weight, g & $732(348)$ & & $741(357)$ & & 0.8 \\
\hline Volume hemicerebrum, $\mathrm{cm}^{3}$ & $32.9(17.3)$ & & $32.9(17.0)$ & & 0.9 \\
\hline Linear growth* per week & +0.17 & 0.95 & +0.17 & 0.95 & 0.2 \\
\hline Volume hemicranium, $\mathrm{cm}^{3}$ & $49.9(24.6)$ & & $50.8(25.3)$ & & 0.7 \\
\hline Linear growth* per week & +0.16 & 0.94 & +0.16 & 0.95 & 0.3 \\
\hline ECF volume $e^{* *}, \mathrm{~cm}^{3}$ & $16.9(7.6)$ & & $17.1(8.0)$ & & 0.6 \\
\hline Linear growth* per week & +0.14 & 0.89 & +0.14 & 0.87 & 0.6 \\
\hline$\%$ ECF (of hemicranium) & $35(3.9)$ & & $35(3.5)$ & & 0.6 \\
\hline Linear decline per week & -0.7 & 0.34 & -0.6 & 0.24 & 0.1 \\
\hline Fluid-brain ratio & $0.54(0.10)$ & & $0.54(0.09)$ & & 0.6 \\
\hline Linear decline per week & -0.018 & 0.34 & -0.014 & 0.24 & 0.2 \\
\hline Brain-weight ratio & $0.44(0.05)$ & & $0.45(0.05)$ & & 0.7 \\
\hline Linear growth per week & +0.001 & 0.26 & +0.001 & 0.18 & 0.2 \\
\hline Sylvian-BPD ratio & $0.146(0.023)$ & & $0.153(0.021)$ & & 0.004 \\
\hline Linear growth per week & +0.005 & 0.42 & +0.004 & 0.40 & 0.5 \\
\hline
\end{tabular}

* Logarithmic transformation. ** Including lateral ventricles. CHD, congenital heart defect; GA, gestational age; ECF, extracerebral fluid; BPD, biparietal diameter. 


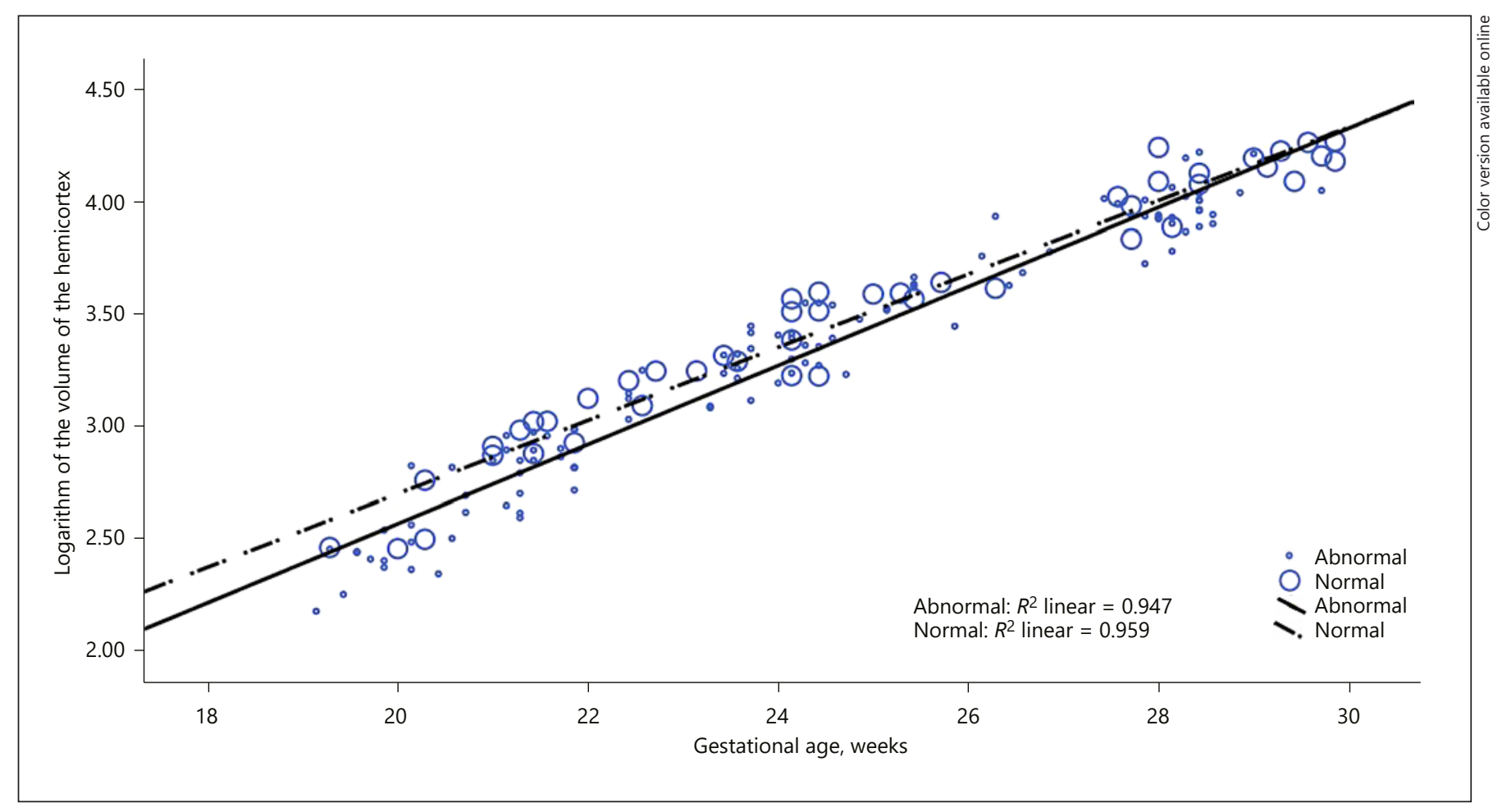

Fig. 3. Linear regression of the volume of the hemicerebrum; normal versus abnormal cerebral oxygen delivery. Linear regression of the logarithmic transformation of the hemicerebrum measurements. No statistical differences were found (linear growth per week +0.16 vs. $+0,18 ; p=0.07$ ).

genation or flow, no significant differences were identified either.

To put our results in perspective further, in our previous retrospective study regarding head circumference in $\mathrm{CHD}$, we also found that especially fetuses with TOF appear to have a small head circumference at midgestation [21]. This finding has also been reported in an MRI study in TOF fetuses [22]. The hypothesis that the specific type of heart defect, such as HLHS and TOF, might play an important role in fetal cerebral development has been suggested in an increasing number of studies $[10,13,26$, $28,29]$. When specific types of CHD are studied in depth, it was furthermore found that neonates with minor CHD such as ventricular septal defects also demonstrate altered brain growth [30], which was the rationale for us to include minor CHD in our current study. Also, in minorlesion PLVCS, with an enlarged sinus coronarius and small left ventricle, it is generally accepted that there might be diminished flow in the aortic arch; therefore, we decided not to exclude these lesions as well. The fact, however, that minor $\mathrm{CHD}$ and $\mathrm{CHD}$ that do not influence cerebral oxygenation or aortic flow also show altered brain growth indicates that factors other than flow and oxygenation might play a role in the pathophysiology of cerebral developmental variations in CHD. Focusing on severe CHD and theoretical oxygen delivery to the brain is therefore insufficient. Genetic or epigenetic factors may also be responsible, as CHD such as VSD, TOF, and DORV are known to be specifically present in children with genetic syndromes. Another finding that supports this hypothesis is the fact that in TOF, submicroscopic chromosomal aberrations with known and unknown significance are frequently found $[31,32]$. Our cohort is unfortunately too small to evaluate the data according to specific type of CHD. Larger, multicenter studies, focusing on specific cardiac lesions, with adequate genetic and postnatal neurodevelopmental follow-up, are needed to avoid case mix bias and/or selection bias, which are common methodological problems in the previous studies. The exploration of the role of small genetic aberrations is needed, such as small microarray variants and possibly whole exome sequencing variants.

Although we acknowledge that there is debate whether MRI or ultrasound is the most sensitive to detect brain 


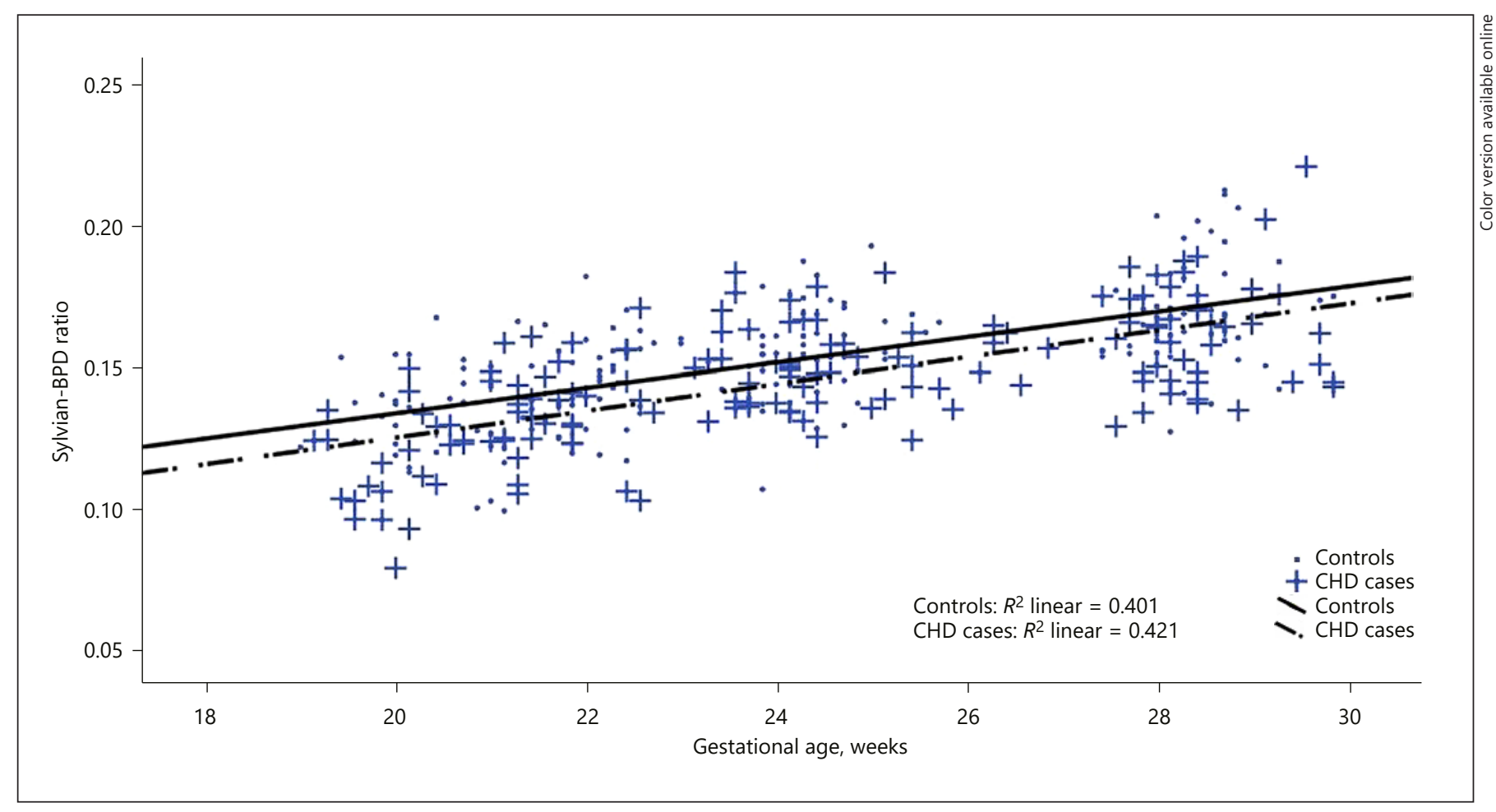

Fig. 4. Linear regression of the Sylvian fissure depth. Linear regression of the relative Sylvian fissure depth (Sylvian-biparietal diameter [BPD] ratio), a smaller ratio implicating a shallower Sylvian fissure. The mean ratio in cases was 0.146 versus 0.153 in controls $(p=0.004)$. Linear growth per week did not differ between cases $(+0.005)$ versus controls $(+0.004 ; p=0.5)$.

abnormalities [33-35], we deliberately chose to perform our study with ultrasound, because ultrasound is cheap and widely available. Therewith, it allows sequentially repeated measurements in a growing fetus [36-38]. We chose to perform the measurements by hand, as the volume data were not suitable for (semi-)automatic volume calculation. Although manually tracing can be prone to interobserver error, our reliability analysis demonstrated excellent inter- and intraobserver variation, possibly because we chose to examine the easily visible distal hemisphere only. Examining the distal hemicerebrum only might seem insufficient, due to asymmetry in the brain; however, the fact that we randomly measured left and right hemispheres in cases and controls justifies this strategy. Our assessment of the brain volumes by VOCAL is slightly comparable to a study in 2015 by Zeng et al. [39] studying complete intracranial volumes in $73 \mathrm{CHD}$ cases, in which a smaller cerebral volume in CHD in the third trimester was found. However, Zeng et al. [39] only included severe CHD with only a single measurement per case, did not report postnatal follow-up nor inter- and intraobserver variation analyses, and our VOCAL measurement rotation angle was more detailed (6- to 9-degree vs. 30-degree steps). Furthermore, in our experience, measuring the cerebral volume after GA 32 becomes less reliable with ultrasound because of extensive shadowing. The latter can also be regarded as a drawback of our study, but we deliberately chose to assess the second and early third trimester, even though previous research has focused on the third trimester, as studies have demonstrated that in certain types of CHD, the possible delay in head growth is already visible at midgestation [20-22].

Our report also includes various extracerebral fluidto-brain ratios and basic assessment of cerebral gyrification in the Sylvian fissure [40]. Firstly, there appears to be a more rapid decrease in relative amount of extracerebral fluid in CHD fetuses; however, this effect was not statistically significant. The Sylvian fissure furthermore is significantly shallower in fetuses with CHD. The clinical significance of these findings has yet to be unveiled. Possibly they are early markers of delayed cerebral maturation, delayed cortical folding, or impending cerebral volume 
growth deflection. The Sylvian fissure has previously been reported to be shallower in CHD, when measured in a comparable manner as our method, but only in the third trimester [41]. However, these results should be interpreted with caution, as the depth of the Sylvian fissure measured in this manner - partly depends on the extracerebral fluid shell around the cortex. Thus, the difference possibly is an expression of a smaller amount of extracerebral fluid in fetal CHD. The depth of the Sylvian fissure may be of predictive value regarding further neurodevelopment, but this finding has not been correlated to postnatal outcome yet, and normal values in healthy fetuses have not been established either. Ultrasound has also been proven capable to analyze cerebral maturation with high detail [42], but to our knowledge, this has not been investigated in fetal CHD yet. Currently, our cohort is being analyzed further to report on more detailed cerebral maturation variables in the future.

Strengths of our study are multiple measurements per case and reduction of selection bias by including all consecutive cases referred to our unit, deliberately including minor CHD cases as well. Also, we excluded cases and controls with extracardiac abnormalities and/or genetic or syndromal anomalies, even if this was only apparent postnatally. The inter- and intraobserver variation analysis demonstrated high concordance. Unfortunately, longterm neurodevelopmental outcome parameters are not available in our cohort yet. Also, brain volume analysis after GA 32 was deemed unreliable due to high levels of acoustic shadowing. This might be the period in which fetal cerebral growth is mostly affected. In our opinion, however, neonatal studies so far cannot exclude that hypoxia in the first days of life in prenatally undetected cases are an important cause for the preoperative cerebral abnormalities. We state that a prenatal origin for neurodevelopmental delay in later life has not been irrefutably proven, especially in other CHD types than HLHS. Therapies like maternal hyperoxygenation should be used with caution, as it is not yet proven beneficial and might even cause less flow to the brain as it causes increased flow towards the pulmonary arteries, leading to a possible steal effect in the brain [43-45].

In conclusion, our study shows no significant difference in hemicerebral volume, extracerebral fluid space, and volume growth between fetuses with isolated $\mathrm{CHD}$ and controls. Only fetuses with specific lesions such as TOF, DORV, and HLHS might have a slightly smaller brain volume at 20 weeks of gestation, but the effect size is very small and wanes with advancing gestation. Fetuses with CHD do have a shallower Sylvian fissure. The etiology and consequences of these findings are unknown. Unfortunately, there are no known fetal ultrasound parameters available in the second trimester for prediction of neurodevelopmental outcome yet.

\section{Disclosure Statement}

The authors report no conflict of interest.

\section{References}

1 Marino BS, Lipkin PH, Newburger JW, Peacock G, Gerdes M, Gaynor JW, et al.; American Heart Association Congenital Heart Defects Committee, Council on Cardiovascular Disease in the Young, Council on Cardiovascular Nursing, and Stroke Council. Neurodevelopmental outcomes in children with congenital heart disease: evaluation and management: a scientific statement from the American Heart Association. Circulation. 2012 Aug;126(9):1143-72.

2 Sarrechia I, Miatton M, De Wolf D, François K, Gewillig M, Meyns B, et al. Neurocognitive development and behaviour in school-aged children after surgery for univentricular or biventricular congenital heart disease. Eur J Cardiothorac Surg. 2016 Jan;49(1):167-74.
3 Owen M, Shevell M, Majnemer A, Limperopoulos C. Abnormal brain structure and function in newborns with complex congenital heart defects before open heart surgery: a review of the evidence. J Child Neurol. 2011 Jun;26(6):743-55.

4 Rosti L, Giamberti A, Chessa M, Butera G, Pomè G, Braga $M$, et al. Pattern of cerebral ultrasound in neonatal heart surgery. Pediatr Med Chir. 2011 May-Jun;33(3):124-8.

5 van Houten JP, Rothman A, Bejar R. High incidence of cranial ultrasound abnormalities in full-term infants with congenital heart disease. Am J Perinatol. 1996 Jan;13(1):47-53.

$6 \mathrm{Te}$ Pas $A B$, van Wezel-Meijler G, Bökenkamp-Gramann R, Walther FJ. Preoperative cranial ultrasound findings in infants with major congenital heart disease. Acta Paediatr. 2005 Nov;94(11):1597-603.
7 Rios DR, Welty SE, Gunn JK, Beca J, Minard CG, Goldsworthy M, et al. Usefulness of routine head ultrasound scans before surgery for congenital heart disease. Pediatrics. 2013; 131(6):e1765-70.

8 Khalil A, Suff N, Thilaganathan B, Hurrell A, Cooper D, Carvalho JS. Brain abnormalities and neurodevelopmental delay in congenital heart disease: systematic review and metaanalysis. Ultrasound Obstet Gynecol. 2014 Jan;43(1):14-24.

9 Donofrio MT, Massaro AN. Impact of congenital heart disease on brain development and neurodevelopmental outcome. Int J Pediatr. 2010. DOI: 10.1155/2010/359390. 
10 Donofrio MT, Bremer YA, Schieken RM, Gennings C, Morton LD, Eidem BW, et al. Autoregulation of cerebral blood flow in fetuses with congenital heart disease: the brain sparing effect. Pediatr Cardiol. 2003 Sep-Oct; 24(5):436-43.

11 Limperopoulos C, Tworetzky W, McElhinney DB, Newburger JW, Brown DW, Robertson $\mathrm{RL}$ Jr, et al. Brain volume and metabolism in fetuses with congenital heart disease: evaluation with quantitative magnetic resonance imaging and spectroscopy. Circulation. 2010 Jan;121(1):26-33.

12 Masoller N, Martínez JM, Gómez O, Bennasar M, Crispi F, Sanz-Cortés M, et al. Evidence of second-trimester changes in head biometry and brain perfusion in fetuses with congenital heart disease. Ultrasound Obstet Gynecol. 2014 Aug;44(2):182-7.

13 Hahn E, et al. The association of fetal growth, cerebral blood flow, and neurodevelopmental outcome in single ventricle fetuses. Ultrasound Obstet Gynecol. 2016 Apr;47(4):4605.

14 Khalil A, Bennet S, Thilaganathan B, Paladini D, Griffiths P, Carvalho JS. Prevalence of prenatal brain abnormalities in fetuses with congenital heart disease: a systematic review. Ultrasound Obstet Gynecol. 2016 Sep;48(3): 296-307.

15 Jansen FA, Everwijn SM, Scheepjens R, Stijnen T, Peeters-Scholte CM, van Lith JM, et al. Fetal brain imaging in isolated congenital heart defects - a systematic review and metaanalysis. Prenat Diagn. 2016 Jul;36(7):60113.

16 Szwast A, et al. Comparative Analysis of Cerebrovascular Resistance in the Fetus with Single Ventricle Congenital Heart Disease. Ultrasound Obstet Gynecol. 2012 Jul;40(1):627.

17 Williams IA, Fifer C, Jaeggi E, Levine JC, Michelfelder EC, Szwast AL. The association of fetal cerebrovascular resistance with early neurodevelopment in single ventricle congenital heart disease. Am Heart J. 2013 Apr; 165(4):544-550.e1.

18 Sun L, Macgowan CK, Sled JG, Yoo SJ, Manlhiot C, Porayette P, et al. Reduced fetal cerebral oxygen consumption is associated with smaller brain size in fetuses with congenital heart disease. Circulation. 2015 Apr;131(15): 1313-23.

19 Mlczoch E, et al. Structural congenital brain disease in congenital heart disease: results from a fetal MRI program. Eur J Paediatr Neurol. 2013 Mar;17(2):153-60.

20 Masoller N, Sanz-CortéS M, Crispi F, Gómez O, Bennasar M, Egaña-Ugrinovic G, et al. Mid-gestation brain Doppler and head biometry in fetuses with congenital heart disease predict abnormal brain development at birth. Ultrasound Obstet Gynecol. 2016 Jan;47(1): $65-73$.
21 Jansen FA, van Zwet EW, Rijlaarsdam ME, Pajkrt E, van Velzen CL, Zuurveen HR, et al. Head growth in fetuses with isolated congenital heart defects: lack of influence of aortic arch flow and ascending aorta oxygen saturation. Ultrasound Obstet Gynecol. 2016 Sep; 48(3):357-64.

22 Schellen C, Ernst S, Gruber GM, Mlczoch E, Weber M, Brugger PC, et al. Fetal MRI detects early alterations of brain development in $\mathrm{Te}$ tralogy of Fallot. Am J Obstet Gynecol. 2015 Sep;213(3):392.e1-7.

23 Andescavage N, Yarish A, Donofrio M, Bulas D, Evangelou I, Vezina G, et al. 3-D volumetric MRI evaluation of the placenta in fetuses with complex congenital heart disease. Placenta. 2015 Sep;36(9):1024-30.

24 Masoller N, et al. Fetal brain Doppler and biometry at mid-gestation for the early prediction of abnormal brain development at birth in congenital heart disease. Ultrasound $\mathrm{Ob}$ stet Gynecol. 2015. DOI: 10.1002/uog.14919.

25 Al Nafisi B, van Amerom JF, Forsey J, Jaeggi E, Grosse-Wortmann L, Yoo SJ, et al. Fetal circulation in left-sided congenital heart disease measured by cardiovascular magnetic resonance: a case-control study. J Cardiovasc Magn Reson. 2013 Jul;15(1):65.

26 Clouchoux C, du Plessis AJ, Bouyssi-Kobar M, Tworetzky W, McElhinney DB, Brown DW, et al. Delayed cortical development in fetuses with complex congenital heart disease. Cereb Cortex. 2013 Dec;23(12):2932-43.

27 Lloyd DF, Rutherford MA, Simpson JM, Razavi R. The neurodevelopmental implications of hypoplastic left heart syndrome in the fetus. Cardiol Young. 2017 Mar;27(2):21723.

28 Hinton RB, Andelfinger G, Sekar P, Hinton AC, Gendron RL, Michelfelder EC, et al. Prenatal head growth and white matter injury in hypoplastic left heart syndrome. Pediatr Res. 2008 Oct;64(4):364-9.

29 Chen Y, Lv G, Li B, Wang Z. Cerebral vascular resistance and left ventricular myocardial performance in fetuses with Ebstein's anomaly. Am J Perinatol. 2009 Apr;26(4):253-8.

30 Matthiesen NB, Henriksen TB, Gaynor JW, Agergaard P, Bach CC, Hjortdal VE, et al. Congenital Heart Defects and Indices of Fetal Cerebral Growth in a Nationwide Cohort of 924422 Liveborn Infants. Circulation. 2016 Feb;133(6):566-75.

31 Fahed AC, Gelb BD, Seidman JG, Seidman CE. Genetics of congenital heart disease: the glass half empty. Circ Res. 2013 Feb;112(4): 707-20.

32 Gelb BD. Recent advances in understanding the genetics of congenital heart defects. Curr Opin Pediatr. 2013 Oct;25(5):561-6.

33 Griffiths PD, Bradburn M, Campbell MJ, Cooper CL, Graham R, Jarvis D, et al.; MERIDIAN collaborative group. Use of MRI in the diagnosis of fetal brain abnormalities in utero (MERIDIAN): a multicentre, prospective cohort study. Lancet. 2017 Feb;389 (10068):538-46.
34 Malinger G, et al. Fetal cerebral magnetic resonance, neurosonography, the multiverse and the brave new world of fetal medicine. Ultrasound Obstet Gynecol. 2017 Dec;50(6): 679-80.

35 Paladini D, Malinger G, Pilu G, Timor-Trisch I, Volpe P. The MERIDIAN trial: caution is needed. Lancet. 2017 May;389(10084):2103.

36 Pistorius LR, Hellmann PM, Visser GH, Malinger G, Prayer D. Fetal neuroimaging: ultrasound, MRI, or both? Obstet Gynecol Surv. 2008 Nov;63(11):733-45.

37 Roelfsema NM, Hop WC, Boito SM, Wladimiroff JW. Three-dimensional sonographic measurement of normal fetal brain volume during the second half of pregnancy. Am J Obstet Gynecol. 2004 Jan;190(1):275-80.

38 Benavides-Serralde A, Hernández-Andrade E, Fernández-Delgado J, Plasencia W, Scheier $\mathrm{M}$, Crispi F, et al. Three-dimensional sonographic calculation of the volume of intracranial structures in growth-restricted and appropriate-for-gestational age fetuses. Ultrasound Obstet Gynecol. 2009 May;33(5): 530-7.

39 Zeng S, Zhou QC, Zhou JW, Li M, Long C, Peng QH. Volume of intracranial structures on three-dimensional ultrasound in fetuses with congenital heart disease. Ultrasound $\mathrm{Ob}$ stet Gynecol. 2015 Aug;46(2):174-81.

40 Alonso I, Borenstein M, Grant G, Narbona I, Azumendi G. Depth of brain fissures in normal fetuses by prenatal ultrasound between 19 and 30 weeks of gestation. Ultrasound $\mathrm{Ob}-$ stet Gynecol. 2010 Dec;36(6):693-9.

41 Peng Q, Zhou Q, Zang M, Zhou J, Xu R, Wang $\mathrm{T}$, et al. Reduced fetal brain fissures depth in fetuses with congenital heart diseases. Prenat Diagn. 2016 Nov;36(11):1047-53.

42 Pistorius LR, Stoutenbeek P, Groenendaal F, de Vries L, Manten G, Mulder E, et al. Grade and symmetry of normal fetal cortical development: a longitudinal two- and three-dimensional ultrasound study. Ultrasound $\mathrm{Ob}$ stet Gynecol. 2010 Dec;36(6):700-8.

43 Szwast A, Tian Z, McCann M, Donaghue D, Rychik J. Vasoreactive response to maternal hyperoxygenation in the fetus with hypoplastic left heart syndrome. Circ Cardiovasc Imaging. 2010 Mar;3(2):172-8.

44 Rasanen J, Wood DC, Debbs RH, Cohen J, Weiner S, Huhta JC. Reactivity of the human fetal pulmonary circulation to maternal hyperoxygenation increases during the second half of pregnancy: a randomized study. Circulation. 1998 Jan;97(3):257-62.

45 Enzensberger C, Axt-Fliedner R, Degenhardt J, Kawecki A, Tenzer A, Kohl T, et al. Pulmonary Vasoreactivity to Materno-Fetal Hyperoxygenation Testing in Fetuses with Hypoplastic Left Heart. Ultraschall Med. 2016 Apr; 37(2):195-200.

Jansen/van Zwet/Everwijn/Teunissen/ Rozendaal/van Lith/Blom/Haak

Rozendaal/van Lith/Blom/Hak 